\title{
FINGER BRUSH, AN ALTERNATIVE FOR REMOVING PLAQUE IN CHILDREN UNDER FIVE YEARS OLD
}

\author{
Burhanuddin Pasiga \\ Department of Dental Public Health Faculty Denstistry Hasanuddin University
}

\begin{abstract}
Finger Brush, An Alternative for Removing Plaque in Children Under Five Years Old

The purpose of the present study was to test the effectiveness of a finger brush in removing plaque compared with that of a regular toothbrush. For this study, 30 subjects were selected and divided into 2 groups. Fifteen subjects received a finger brush, another group of subjects received a regular toothbrush. The amount of dental plaque was scored by the modified PHP method. Plaque scored was carried out at five areas per tooth. The results showed that the overall reduction in plaque was $67,25 \%$ for the regular toothbrush and $44,93 \%$ for the finger brush; it was a non significant difference ( $p>0,170)$. The plaque removing efficacy of the finger brush was poorest at the mesial area $(28,1 \%$ plaque reduction) compared with that of the regular toothbrush ( $68,8 \%$ plaque reduction). It was concluded that the plaque by means of finger brush could be an acceptable alternative to the use for children under five years age. Indonesian Journal of Dentistry 2006; Edisi Khusus KPPIKG XIV:224-228
\end{abstract}

Key words: finger brush; plaque; toothbrush

\section{Introduction}

The most important method for controlling dental caries is the control of plaque on the tooth and gingival surfaces. Thorough plaque control has been considered as an essential factor in the prevention and treatment of caries and periodontal diseases. ${ }^{1-2}$

Plaque can be controlled using mechanical dan chemical agents. Mechanical cleaning was aimed to remove plaque by patient's psychomotor abilities using special tools such toothbrush, toothpick, and dental flos. ${ }^{1}$ Since the earliest recorded evidence of the natural toothbrush as a plaque fighters, the evolution of toothbrushes has led to the development of three distinct technologies, manual, electro mechanical and ultrasonic brushes. ${ }^{3}$

It is known that the three basic circles from Paul Keys,1960 cit Leal SC ${ }^{(4)}$ display the basic etiological factors of dental caries. One of them is undoubtedly the microorganism, which accumulates and forms biofilm known as dental plaque. Although there is no scientific based evidence correlating biofilm and dental caries, it is accepted that plaque removal is a very advisable procedure for oral health maintenance in preschool children. ${ }^{4}$

Among children at least 2 years of age, the prevalence of Early Childhood Caries (ECC) was $73,6 \%$. Early Childhood Caries is a particularly destructive form of tooth decay that afflicts young children. Schroth et.al (2005), reported that the prevalence of early Chilhood caries was $53,7 \%$ in Manitoba. Traditional strategies for preventing caries have improved the oral health of many children $^{5}$

Brushing children teeth should begin at early age, around 24 months. It is necessary to clean the 
teeth daily as plaque (a sticky, invisible film of bacteria and left-over food debris) will be formed in the toddler's mouth, just as it does in our own. ${ }^{6}$

Children will need help brushing their teeth until they are around the age of 7 to 8 years old. ${ }^{7}$ Even before the child actually has teeth, it is important to perform mouth care. Using a damp wash cloth or piece of gauze, gently rub it over your infant's gums to help clean the mouth. ${ }^{7}$

Recently, the I-Brush, called the finger brush has been introduced. It is a new manual brushing method for people to control the amount of plaque. This brush is mounted on the index finger of the brushing hand. It uses the agility and sensitivity of the finger ${ }^{8}$ These brushes can be used as an alternative way to removing plaque for child under five years of age. Thus, this study assessed the effectiveness of 2 methods for toothbrusing in children with under five year old ( range 2-3 years old).

\section{Material and Methods}

The present study was carried out at Posyandu RW V Kelurahan Mariso Kecamatan Mamajang Makassar. Thirty children, under 5 years old (range 2 - 3 years old) were selected for this study and were randomly divided into 2 groups. The parents of the selected child signed an informed consent.

The Finger brush, is a new approach in toothbrush design and can be compared to an elastic stocking topped by microfibers, which is self made. This stocking is placed over a finger, preferably the index finger, and acts as a "finger brush"(see Figure1).

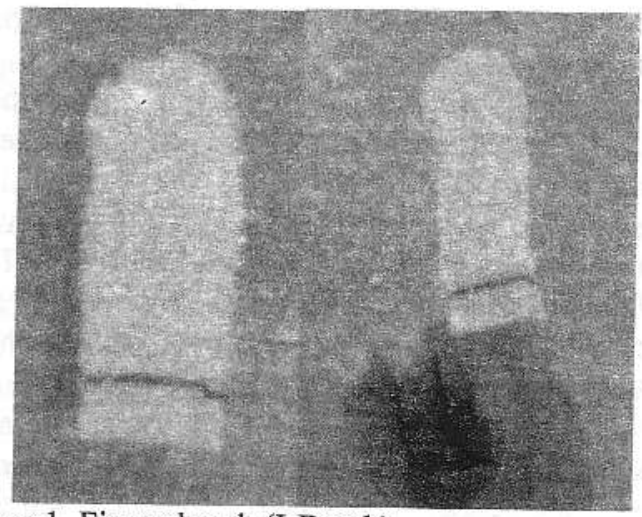

Figure1. Finger brush (I-Brush)

The control brush was a regular manual toothbrush. The toothbrushes and toothpaste of the same brand were given to all children that participated in this study. Each child brushed his or her teeth under their parent suppervision, according to the instructions received before. Plaque disclosing was carried out before and after brushing for plaque index comparison.

In this experiment, the amount of dental plaque was scored by PHP (patient hygiene performance) method by Podshaley dan Haley ${ }^{(9)}$ at five areas per tooth (see Figure.2). Total number of tooth areas for score per subject was 60 . Plaque is assessed for each tooth area $(A-E)$ and was scored using the following scale: $0=$ Absent; 1 = Present.

Facial and lingual surfaces of all teeth were scored and a mean plaque index (MPI) is calculated for each subject at each examination. ${ }^{10}$

$$
\frac{\text { Total number of tooth areas with plaque present }}{\text { Total number of tooth areas scored }}
$$

The data were statistically analyzed utilizing the Student t-test and the comparison of two proportions.
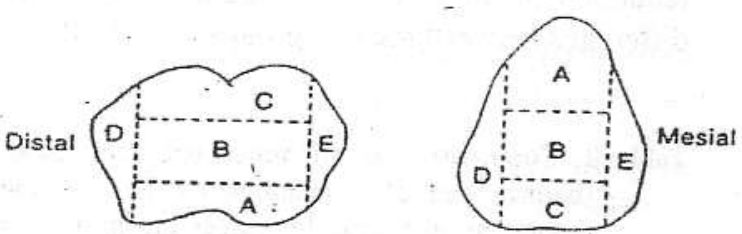
A. Gingival one third of middle area
B. Middle one third of middle area
C. Incisal or occlusal one third of middle area
D. Distal area
E. Mesial area

Fig.2. Plaque scoring-the PHP method, modified (From Jong AW. Dental public health and community dentistry. St. Louis, Mosby Company. 1981; p.80. $)^{(9)}$.

\section{Result}

The overall means with respect to plaque removal are presented in Table 1 and Table 2. This provides the base- and end plaque scores for the finger brush and the manual toothbrush as well as the plaque reduction in terms of percentages. In Table 1, appeared of all groups experiment the 
significant difference of number plaque of before and after brushing $(\mathrm{p}<0,01)$.

Table 1. The mean and standard deviation values of numbers plaque areas at base line (before) and after brushing of all groups

\begin{tabular}{|c|c|c|c|c|c|c|}
\hline \multirow{2}{*}{ Groups } & & \multicolumn{2}{|c|}{ Base line (before) } & \multicolumn{2}{|c|}{ after } & \multirow{2}{*}{ Sig } \\
\hline & & Mean & SD & Mean & SD & \\
\hline $\begin{array}{l}\text { Finger } \\
\text { brush }\end{array}$ & 15 & 30,867 & 6,423 & 17,000 & 7,838 & $0,001^{*}$ \\
\hline $\begin{array}{l}\text { Regula } \\
\text { r brush }\end{array}$ & 15 & 26,667 & 8,129 & 8,733 & 5,725 & $0,001^{\text {* }}$ \\
\hline
\end{tabular}

* Before-after $\mathrm{t}$ test $\rightarrow \mathrm{P}<0.005 \rightarrow$ significance $\mathrm{SD}=$ Standard Deviation

In Table 2, the manual toothbrush removed more plaque (mean plaque reduction of $67,25 \%$ ) compared with the finger brush (mean plaque reduction of $44,93 \%$ ), there seemed no significant difference between the two groups $(p=0,170)$.

Table 2. Comparison of difference between base line (before) and after examination for percentage reductions in plaque for finger brush and manual brush techniques.

\begin{tabular}{|c|c|c|c|c|}
\hline Group & $\mathrm{n}$ & Mean (\%) & SD & Sig \\
\hline $\begin{array}{l}\text { Finger } \\
\text { brush }\end{array}$ & 15 & $\begin{array}{c}13,867 \\
(44,93 \%)\end{array}$ & 6,675 & \multirow[t]{2}{*}{$\begin{array}{c}0,170^{*} \\
\text { (ns) }\end{array}$} \\
\hline $\begin{array}{c}\text { Manual } \\
\text { brush }\end{array}$ & 15 & $\begin{array}{c}17,933 \\
(67,25 \%) \\
\end{array}$ & 8,979 & \\
\hline
\end{tabular}

* Independent Student $\mathrm{t}$ test, $p<0,05 \rightarrow$ Significance

$\mathrm{SD}=$ Standard Deviation; ns $=$ non significant

In Table 3, appeared that the highest difference in plaque reduction was found on the site $\mathrm{D}$ and $\mathrm{E}$ (mesial and distal area) were $\mathrm{p}<0,05$. For site A, B and $C$ there were no significant difference in plaque reduction between finger brush and manual brush technique $(p>0,5)$. For interproximal scores, for distal area, the regular toothbrush had an adjusted mean reduction in plaque scores that was $32,8 \%$ higher than that of the finger toothbrush technique and $40,7 \%$ for mesial area.
Table 3. Comparison of difference between base line (before) and after examination for percentage reductions of plaque in each tooth area for finger brush and manual brush techniques.

\begin{tabular}{lccc}
\hline \multicolumn{1}{c}{ Tooth Area } & $\begin{array}{c}\text { Finger } \\
\text { brush }\end{array}$ & $\begin{array}{c}\text { Manual } \\
\text { brush }\end{array}$ & Sig* \\
\hline $\begin{array}{l}\text { Gingival one third of } \\
\text { middle area (A) }\end{array}$ & $46,4 \%$ & $59,1 \%$ & 0,500 \\
$\begin{array}{l}\text { Middle one third of } \\
\text { middle area (B) }\end{array}$ & $58,3 \%$ & $86 \%$ & 0,475 \\
$\begin{array}{l}\text { Incisal or occlusal } \\
\text { one third of middle } \\
\text { area (C) }\end{array}$ & $69,5 \%$ & $83,8 \%$ & 0,898 \\
$\begin{array}{l}\text { Distal area (D) } \\
\text { Mesial area (E) }\end{array}$ & $31,1 \%$ & 63,9 & $0,036^{* *}$ \\
\hline * Student $\mathrm{t}$ test , ${ }^{* *} \mathrm{p}<0,05 \rightarrow$ Significant &
\end{tabular}

\section{Discussion}

In Table 1, there seemed significant differences of means in plaque before and after brushing for all groups. These results indicated that finger brush also effective for removing plaque. These findings are similar to that of the Graveland, et al (2004).

Unkel et al. (1995), suggested that chronological age was a reasonable predictor of toothbrushing ability and that manual toothbrushing skills are acquired after approximately four to five years. ${ }^{11}$ Ogasawara Cit Leal SC affirm that it is possible to give effective guidance in toothbrushing to preschool children as long as the instructions are adapted to their age. ${ }^{4}$

Nevertheless, it is generally known that toothbrushing by children under ten years of age is inefficient. ${ }^{11}$ This difficulty can be explained by the lack of motivation and poor manual dexterity normal to this ag. ${ }^{12}$

Oral hygiene instructions through educational lectures resulted in highly significant improvements in oral health . However, there is evidence that the development of grammatical understanding in very young children continues for several years. This could explain the difficulty found in the training and practice of oral hygiene techniques in preschool children using only verbal instructions. ${ }^{13}$

Few studies provided reports on finger brushing but these described the effects in relation to caries incidence. ${ }^{16}$ Effective plaque removal instruction can be taught when the child is an active part of oral hygiene education. Instructions should be given according to the child's degree of readiness 
for toothbrushing and should include systematic training and reinforcement. Although manual dexterity and ability are necessary, intensive individual training is essential . Children should be educated in oral self-care according to their status of psychological development. ${ }^{11}$

Graveland, et.al, reported that on approximal vestibular surfaces the finger toothbrush had a $55 \%$ plaque reduction and the manual toothbrush had a $77 \%$ plaque reduction ${ }^{(8)}$. Result of these studies are that the overall reduction in plaque was $67,25 \%$ for the manual toothbrush and $44,93 \%$ for the finger brush, and it is a no significant difference $(p>0,170)$. The plaque removing efficacy of the finger brush was poorest at the mesial area $(28,1 \%$ plaque reduction) compared that of manual toothbrush ( $68,8 \%$ plaque reduction).

The finger brush resembles the disposable soft sponge on a stick and have been dispensed to hospital patients for intra-oral cleansing as early as the year $1970 \mathrm{~s}^{(15)}$. They are particularly used for oral care in medically compromised and immune compromised patients, to reduce the risk of oral and systemic infection. Lefkoff et al. (1995) studied the effectiveness of such a disposable foam brush on plaque. $^{16}$

The interdental gingiva fills the embrasure between two teeth, apical to their contact point. This is a protected area when teeth are in normal position. Most gingival diseases start in this interdental area (Lo"e 1979). The ain reason for the difficulty in removing approximal plaque is that people have difficulty in allowing the bristles to make a proper scouring action across tooth and gingival surfaces ${ }^{(13)}$ . Foam swabs have been found to be particularly ineffective in removing plaque, which had accumulated in areas between teeth. ${ }^{15}$

Toothbrushing, as all habits of hygiene, is acquired during the socialization process of the child. When this habit is taught in early childhood, it is naturally ingrained in the daily routine of the child, with only positive reinforcement needed later. ${ }^{17,18}$

Children should be encouraged to brush their own teeth. However, they do not have the skill to use a toothbrush correctly until about seven or eight years of age. It is advisable for a parent to supervise toothbrushing until the child is able to manage the correct technique.

\section{Conclusion}

The results show that the finger brush removed less plaque than a regular manual toothbrush. In particular the approximal (mesial and distal) plaque reduction was poor in comparison with the manual toothbrush. Based on these results, it is concluded that there although no beneficial effect of finger brush but if a toothbrush cannot be used in hospitalised patients or brushing toddlers or child under five year of age, may be an alternative for removing plaque in children under five years old with non cooperative for brushing of teeths.

\section{References}

1. Carranza FA. Glickman's. Clinical Periodontology. 6th ed. Philadelphia: WB Saunders Co, 1990.

2. Manson JD, Eley BM. Buku Ajar Periodonti (Outline of periodontics)/ Manson JD, Eley BM, alih bahasa Anastasia S, editor Susianti Kentjana Jakarta: Hipokrates, 1993

3. Vandana KL, Penumatsa GS. A Comparative Evaluation of An Ultrasonic and A Manul Toothbrush on The Oral Hygiene Status and Stain Removing Efficacy. J Indian Soc Pedo Prev Dent 2004; (22)1: 13.

4. Leal SC, Bezerra ACR, deToledo OA. Effectiveness of Teaching Methods for Toothbrushing in Preschool Children. Braz Dent J 2002; 13(2).

5. Schroth RJ, Moore P, Brothwell DJ. Prevalence of Early Chilhood Caries in Manitoba Communities. $J$ Can Dent Assoc 2005; 7(18):567.5.

6. University Health Care. Dental \& Oral Health. Brushing and Toothpaste. Available on http://uuhsc.urah.edu. Accessed at 20 Feb 2006.

7. Health department of Western Australia. Brushing Toddler's Teeth. Avaialable on http://www.q.net.aul Dentalservices.html. Akses 20 Per 2006.

8. Graveland MP, Rosema NAM, Timmerman MF, Van der Weijden GA. The Plaque Removing Efficacy of A Finger Brush (I-Brushs). J Clin Periodontol 2004; 31: 1084-1087.

9. Jong AW. Dental Public Health and Community Dentistry. St Louis: Mosby Co, 1981:80.

10. Terézhalmy GT, Bsoul SA, Bartizek RD, Biesbrock AR. Plaque Removal Efficacy of A Prototype Manual Toothbrush versus An ADA Reference Manual Toothbrush with and without Dental Floss. $J$ Contemp Dent Pract 2005;6(3):001-13.

11. Tsamtsouris A, White GE, Clark ER. The Effect of Instruction and Supervised Toothbrushing on The Reduction of Dental Plaque in Kindergarten Children. J Dent Child 1979;36:204-9.

12. Stutcliffe P, Wishart WA, Naomi C. Supervised Toothbrushing In A Nursery School. Brit Dent $J$ 1977;147:192-4. 
13. Unkel JH, Fenton $\mathrm{SJ}$, Hobbs $\mathrm{G}$, Frere $\mathrm{CL}$. Toothbrushing Ability is Related to Age in Children. J Dent Child 1995;5:346-8.

14. Grossman E, Proskin H. A Comparison of The Efficacy and Safety of An Electric and A Manual Children's Toothbrush. $J$ Am Dent Assoc 1997;128:469-74.

15. Simmons $S$, Smith R, Gelbier S. Effect of Oral Hygiene Instruction on Brushing Skills in Preschool Children. Comm Dent Oral Epidemiol 1983;11:1938.
16. Kane AW, Faye B, Toure B, Sarr M, Cisse D, Diop O, Diallo B. Oral Hygiene Habits and Denta! Caries among Students. Investigation Of 150 Students in University Housing in Dakar, Senegal. Odontostomatologie Tropicale 2001; 24: 16-21.

17. Pearson LS, Hutton JLA. Controlled Trial To Compare The Ability of Foam Swabs and Toothbrushes to Remove Dental Plaque. $J A d v$ Nursing 2002; 39: 480-9.

18. Lefkoff MH, Beck FM, Horton JE. The Effectiveness of A Disposable Tooth Cleansing Device on Plaque. $J$ Periodontol 1995; 66: 218-21 